\title{
Virtual and Augmented Reality in Language Acquisition
}

\author{
Viktoria Dobrova \\ Foreign Languages Department \\ Samara State Technical \\ University \\ Samara, Russia \\ victoria_dob@mail.ru
}

\author{
Polina Labzina \\ Foreign Languages Department \\ Samara State Technical \\ University \\ Samara, Russia \\ labzinapg@mail.ru \\ Evgenia Elizarova \\ Foreign Languages Department \\ Samara State Technical \\ University \\ Samara, Russia \\ eva240281@mail.ru
}

\author{
Natalia Ageenko \\ Foreign Languages Department \\ Samara State Technical \\ University \\ Samara, Russia \\ 1-2402@yandex.ru
}

\author{
Lilia Nurtdinova \\ Foreign Languages Department \\ Samara State Technical \\ University \\ Samara, Russia \\ liliandrr@gmail.com
}

\begin{abstract}
Studying the mechanisms of language and speech abilities showed that the most effective method of learning a foreign language is a method of total immersion as students enter the natural language environment and are in it constantly. But the learning process in the classroom, no matter how organized, creative and communicative it is, cannot replace the real experience of teaching. As the most important factors for the effective foreign language learning are the language environment and the motivation, thus the development of new motivational language learning environments, including virtual reality (VR), augmented reality (AR) and 3D environment, are the basic elements of the learning process. The development of $V R$ and $A R$ technology allows expanding the boundaries of science and introducing innovations in all spheres of human activity. In the educational establishments of the USA and China VR and AR environments are already widely used, but in Russia VR is used only in a few schools and universities and AR has not been used at all. The group of teachers of Samara State Technical University designed the new generation educational course of English based on the VR and AR technology that creates a real situational interaction in which the student can receive certain information, to carry out scientific and educational elements, project activities. In such educational space VR/AR helps students to understand the phenomena and situations that cannot be understood and explained in the traditional techniques, become part of the real world through the simulation. In general, VR/AR is an ideal learning environment, and the opportunities of its technologies for teaching have an extremely high potential for application.
\end{abstract}

Keywords - virtual reality, learning environment, immersion method, facilitation in education, interactivity in education, foreign language skills, autonomy of learning, innovative teaching methods.

\section{INTRODUCTION}

The study of the mechanisms of language and speech abilities, processes of speech perception and speech production showed that the most effective method of teaching a foreign language is the full immersion method, since students get into the natural language environment and are constantly in it. As the possibility of living and studying abroad for the majority of those who study a foreign language is not generally available, methodologists and teachers are in constant search of alternative methods of teaching and creating educational models close to the natural language environment. This includes short-term language courses abroad, bilingual education, international projects on academic mobility, and "active learning" techniques, such as business role plays, video, the "immersion" methods, the "real situations" method, cases and so on.

Although such efforts make their contribution to the process of teaching the language, bringing it closer to real life, it is worth noting that they do not bring the desired, ideal result. The process of learning in a class, however organized and communicative, cannot replace the experience of real language learning. Researchers emphasize that the study of a foreign language in textbooks and in the classroom as a whole limits the progress in learning and using the language, which is especially noticeable in such areas as teaching vocabulary, speech, spontaneous speech and intercultural competence [1].

These shortcomings emphasize, on the one hand, the importance of the language environment for effective learning, and on the other hand, the leading role of motivation in the study of language. Accordingly, the development of new motivational environments for language learning, including virtual reality and 3D environments, and the use of meaningful, engaging, culturally and professionally oriented learning materials are the basic and necessary elements of the learning process. The development of virtual reality technologies allows expanding the boundaries of science and introducing innovations into all spheres of human activity.

Information technology as a whole is now a ubiquitous presence in all educational settings as well as places in which people work [2]. In schools in the USA, China and Japan, such 
virtual technologies and virtual environments are already widely used, and virtual lessons are very popular. In Russia, the technologies of augmented and virtual reality are used only in some schools and universities. So far this is not included in the compulsory education program, but several examples have already been realized: thus, the supplemented reality in teaching is applied in the form of adding interactive material to ordinary textbooks. When you point the camera phone or tablet on the picture in the textbook a student can see, for example, the form of a medieval castle in $3 \mathrm{D}$, to view it from different angles on the screen of the device. You can watch a video of a chemical reaction or even conduct a virtual experiment, mixing virtual chemical elements.

$\mathrm{H}$. Rheingold notes that the problem of higher education today is that approaches to teaching and learning became old and not much effective. He suggests: "rather than lecture halls with rowed seats being the predominant physical learning space for learning and teaching in higher education, learning spaces need to include: physical/virtual, formal/informal, blended, mobile, personal, and professional learning spaces that need to consider flexibility, adaptability, and time. They need to mirror contemporary learning and teaching strategies that emphasize independent and peer-based learning in both physical and virtual learning spaces." [3]. In higher education in Russia, virtual reality technologies have been used for several years, although their application is of a single nature.

\section{TERMS "VIRTUAL", "VIRTUALITY", "VIRTUAL REALITY"}

Originally, the epithet "virtual" (from Latin virtus imaginary) was introduced by specialists in quantum physics to designate ephemeral (unobservable) elementary particles that arise and exist only in the process of interaction of other particles. N.A. Nosov notes that in ancient philosophy and medieval scholasticism the term virtus (virtual) was one of the central categories, denoting a possible, potential, referring to the reality of a different (higher) order [4]. However, then its meaning changed radically: "virtual" began to mean the opposite of material, ephemeral, trying to artificially recreate reality. Subsequently, this concept was used to designate three-dimensional computer macromodels, and then rapidly expanded its terminological boundaries, becoming one of the universal characteristics of information activities as such.

For the first time, the term "Virtual Reality" (VR) was introduced by the computer programmer Ya. Lanier in 1988 and was defined as "a combination of high-speed computers, advanced programming techniques, and interactive devices designed to make computer users feel they have stepped into another world, a world constructed of computer data " [5].

H. Reingold defines VR as an experience in which a person «is surrounded by a three-dimensional computer-generated representation» [6], where it is possible to move around in the virtual world, to see it from different angles, to reach into it, to grab it, to reshape it, thus getting experience. Currently, VR generally describes the technologies of head-mounted displays, arm-mounted displays and surround-screen projection-based displays. A head-mounted display consists of a pair of miniature displays positioned in goggles or in a helmet strapped to the user's head so that each eye sees one display. Traditionally, head-mounted displays have been used to provide high-quality stereo visualization of $3 \mathrm{D}$ virtual environments. An arm-mounted display or BOOM is like a head-mounted goggle display but is suspended from an articulated arm and is held to the viewer's face with handles. Surround-screen virtual environments are semi immersive visual displays that are capable of providing very wide-fieldof-view visualization and some of them are even capable of fully covering the human field of view.

S. McGlashan and T. Axling understand by VR «graphical two dimensional or three dimensional interface for interaction between the user and the computer that applies to computersimulated environments that can simulate places in the real world, as well as in imaginary worlds» [7].

Having analyzed the definitions of the concept of "virtuality", proposed by various researchers, we can distinguish its main features:

- $\quad$ relevance: virtual objects exist only up to date, only "here and now";

- $\quad$ autonomy: the laws of the existence of virtual objects do not coincide with the laws of the existence of reality, generating them;

- $\quad$ generation: these objects are produced by the activity of some other reality external to them, and exist only while this activity lasts;

- interactivity: virtual objects can interact with the reality that generates them as ontologically independent of it;

- ephemeral: virtual objects are artificial and changeable;

- non-materiality of impact: not being material, virtual objects can produce effects characteristic of the real;

- fragmentation: the freedom to enter virtual reality and the freedom to exit from ensure the possibility of arbitrary interruption and renewal of its existence.

In pedagogy, "VR" is mainly used as a special information space, where the student can receive certain information, carry out contacts, elements of scientific and educational and project activities.

\section{TERM "AUGMENTED REALITY"}

Nowadays "Augmented reality" (AR) is understood as a live direct or indirect view of a physical, real-world environment, the elements of which are "augmented" by computer-generated or extracted real-world sensory input such as video, graphics, sound, haptics, etc. As a whole, it can be related to a more general concept of computer-mediated reality, in which a view of reality is modified by a computer. AR enhances the current perception of reality, in contrast to VR where the real world is not a simulated one. AR is used in order to make the experienced environments or situations richer, brighter and better.

Originally, the immersive augmented reality experiences were used in the spheres of entertainment and game business, but now other business industries are also getting interested in $\mathrm{AR}$, such as education, management of the information flood and organization of distant meetings. AR has a lot of potential 
in gathering and sharing tacit knowledge. Augmentation techniques are typically performed in real time and in semantic context with environmental elements.

With the help of advanced AR technology the information about the surrounding real world becomes interactive and digitally manipulable, as it is overlaid on the real world. This information can be virtual or real, e.g. seeing other real sensed or measured information such as electromagnetic radio waves overlaid in exact alignment with where they actually are in space. AR brings out the components of the digital world into a person's perceived real world. One example is an AR Helmet for construction workers which display information about the construction sites.

Augmented reality has been explored for many applications today, for example it was applied to aid archaeological research by augmenting archaeological features onto the modern landscape, that allowed archaeologists to formulate possible site configurations from extant structures. It is also used in architecture, visual arts, commerce, medicine, navigation, etc. AR is also transforming the world of education, where content may be accessed by scanning or viewing an image with a mobile device. Textbooks, flashcards and other educational reading material contained embedded "markers" that, when scanned by an AR device, produced supplementary information to the student rendered in a multimedia format. Instead of remaining passive recipients, students would become active learners, who are able to interact with their learning environment. For example, AR simulations of historical events could come alive. Or anatomy students could visualize different systems of the human body in three dimensions.

\section{VR/AR EDUCATIONAL ENVIRONMENT}

Although the application of VR/AR with interactive control capabilities and user focus was originally designed for such areas as healthcare (visualization of surgical operations), architecture (visualization of large-scale design projects), aviation (visualization of flight for training pilots), it can be widely used in teaching due to its universal character and the possibility of user interaction in any three-dimensional world, real or abstract. The virtual world can be a building, a human body, an underwater world, space, a museum, a dinner, etc. VR/AR radically transforms the principle of visualization, creating a semblance of real objects through information modeling. As a result, the student gets almost the same (or stronger) personal experience in visual, auditory, tactile, olfactory perception, in the implementation of actions, as well as in real interaction with similar situations. VR/AR is one of the pinnacle of computerized learning. It achieves "overstimulation" of the sense organs (similar to obtaining real perceptual experience), which is the basis of learning, including intellectual learning.

Virtual reality offers unique learning and teaching experiences due to its ability to provide real-time threedimensional visualization and afford various types of interactivity within virtual learning environments [8]. Many educators and researchers have pointed out the significance of using $\mathrm{VR} / \mathrm{AR}$ technology and $\mathrm{VR} / \mathrm{AR}$ environment for engaging learners in the learning process, and thus VR/AR based applications and software are ubiquitously used in various educational contexts $[9 ; 10 ; 11 ; 12 ; 13 ; 14 ; 15]$.

Thus there appeared such a concept as the educational environment of VR/AR. It describes everything from 3D animation on a personal computer to simulating entire networks. In the educational space, VR/AR helps students understand phenomena and situations that do not lend themselves to understanding and explanation within the framework of traditional methods, to become part of the real world through simulation.

B. Dalgarno enumerates the following characteristics of the educational environment of VR:

- The environment is modelled using 3D vector geometry, so that objects are represented using $\mathrm{x}, \mathrm{y}$ and $\mathrm{z}$ coordinates describing their shape and position in 3D space;

- The user's view of the environment is rendered dynamically according to their current position in 3D space, that is, the users can move freely through the environment and their views are updated as they move;

- At least some of the objects within the virtual environment respond to user action, for example, doors might open when approached and information may be displayed when an object is selected;

- Some environments include 3D audio, that is, audio that appears to be emitted from a source at a particular location within the environment [16].

Dalgarno's model can be represented in the following way: (see Fig.1).

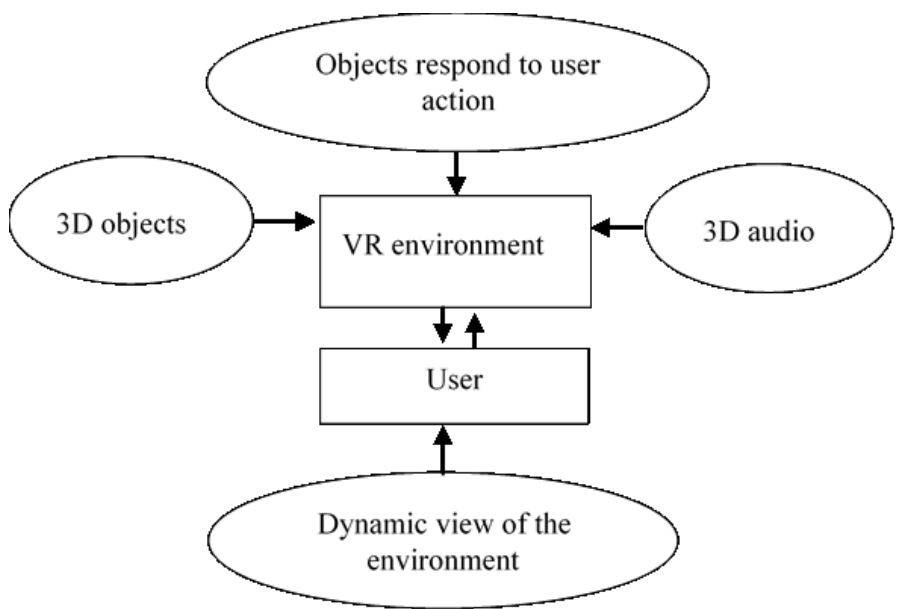

Fig.1. Characteristics of VR learning environment by B.Dalgarno

J. Wann and M. Mon-Williams suggested a different point of view on the educational environment of VR/AR. They believe that the main component of the environment is the ability to interact with the help of direct control: «VR learning environment, therefore, has the potential to provide a powerful interactive simulation of three-dimensional structures in a virtual world environments» [17]. 
Many researchers [18; 19] believe that VR/AR makes it possible to find and operate in environments that are not accessible to people due to time, distance, scale and security.

We singled out the following possibilities of VR/AR in education:

1) Visibility. Using 3D-graphics, you can detail the various processes and phenomena [20;21]. VR/AR is able not only to provide information about the phenomenon itself, but also to demonstrate it with any degree of detail.

2) Security. Surgical operation on the heart, control of a superhigh-speed aircraft, fire - you can immerse the viewer in any of these circumstances without the slightest threat to life.

3) Involvement. VR/AR allows you to change scenarios, influence the course of an experiment, or solve problems in a playable and understandable form. During the virtual lesson you can see the world of the past through the eyes of a historical character, go on a journey into space, make an ascent to Mount Everest.

4) Focusing. The virtual world, which surrounds the viewer from all sides, will allow to concentrate entirely on the material and not be distracted by external stimuli.

5) Presence. A first person view and a sense of your presence in the painted world is one of the main features of virtual reality. This allows you to conduct lessons entirely in VR/AR.

The teacher of a foreign language can create real situational interaction with the help of VR/AR, for example, such as an interview at employment, the situation in a restaurant, at an airport, etc. Virtual space can vary depending on the objectives, language level, time frame, number of participants, real or animated characters, used devices, etc. It offers students flexible and convenient access that is a key driver for the use of technology in learning [22]. Using VR/AR helps to overcome many difficulties of traditional learning.

The analysis of practical activities on the creation of a software and hardware virtual reality complex for the study of a foreign language for special purposes has made it possible to outline the following principles that will direct the educational process in the required way:

- facilitation;

- autonomy;

- interactivity;

- professional orientation;

- multimodal presentation of educational information;

- independent educational activity.

The key point is that the language environment determines the effective acquisition of foreign language skills, and the principle of facilitation is realized by means of real professional conditions simulation in a virtual environment.

All participants using 3D-model can navigate easily through virtual space with the help of special controllers and interact with any objects of study, for example, using the buttons, switches, toggle switches, etc. provided by the program. The virtual environment and the objects with which learners interact can change according to the actions of participants. So, for example, a trainee can interact with a virtual customs control officer, solving the programmed problem situations. Such organization of the interaction process corresponds to the principle of interactivity, which ensures involvement in active communication activities on professional subjects and motivation to master the discipline [23].

The result of the realization of the principle of independent educational activity is traced in the development of flexibility and fitness to perform the assigned tasks in an individual way. Following the principle of autonomy is revealed in overcoming the psychological barrier, self-doubt, it provides a transition to the individual character of learning, featured by a high level of motivation [24].

The principle of professional orientation is directly related to the content of the training program. Depending on the situation modeled, the teacher can train or check the skills of students, how to behave in a particular situation, to teach to use complex techniques.

The considered principles of the formation of the process of teaching a foreign language for special purposes with the help of virtual reality acquire special significance for the professional formation of a future specialist, since the content of instruction, the educational material intended for students' development of skills and proficiency in language correspond to the professional orientation; forms and methods of teaching the language with the use of computer technologies contribute to a positive perception of the chosen profession by the future specialist; ensure the development of his creative thinking and the consolidation of professional and socio-psychological knowledge [25].

\section{NEW GENERATION VR/AR COURSE OF ENGLISH}

The group of teachers and students of Samara State Technical University de-signed the new generation educational course of English based on the VR/AR technology that creates a real situational interaction in which the student can receive certain information, to carry out contacts, scientific and educational elements and project activities [26]. In such educational space VR/AR helps students to understand the phenomena and situations that cannot be understood and explained in the traditional techniques, become part of the real world through the simulation.

For the developing of a comprehensive training system in a foreign language using VR/AR technologies "Virtual Customs", the concept of three-dimensional modeling of technical systems and processes using software development tools was used, one of which is the Unity3D environment. It should be mentioned, that in the soft-ware design market of today there are various software development tools each of which has its own advantages and disadvantages [27]. The use of the mentioned concept gives wide possibilities for modeling various scenarios for the functioning of technical systems, both at design stages and during the operation.

To study the aspects of the real object and its linguistic features, a customs point was chosen, that is located at the international airport. Students are provided with VR glasses: Oculus Rift or HTC Vive. Further, the teacher or the student himself launches the training system "Virtual Customs", which should solve the following set of tasks: 
- the functioning of the system in two modes: training and interactive with the possibility of testing the student;

- $\quad$ in the training mode, the student makes a virtual inspection of the customs station as a passenger. Then the standard procedure for passing passport and customs control using standard dialogues in a foreign language follows. At the same time, on the screen of the virtual reality device, subtitles of the dialogues of the passenger and the customs personnel are displayed;

- $\quad$ in the interactive mode, the student is offered to undergo another virtual check at the customs office at the airport but in the role of a customs officer.

Thus, the trainee is in the customs zone of the international airport and gets the opportunity to navigate through it, entering into dialogues with the attendants and studying the inscriptions on the customs equipment and stands. To move around the halls, the student uses the Leap Motion tracking device. At the moment, there are two active halls, the socalled "Green Channel" and "Red Channel".

Figure 2 shows the employee of the customs station, who meets the passenger at the entrance. He greets the passenger and tells him about the responsibilities and duties of the customs officer and the customs service.

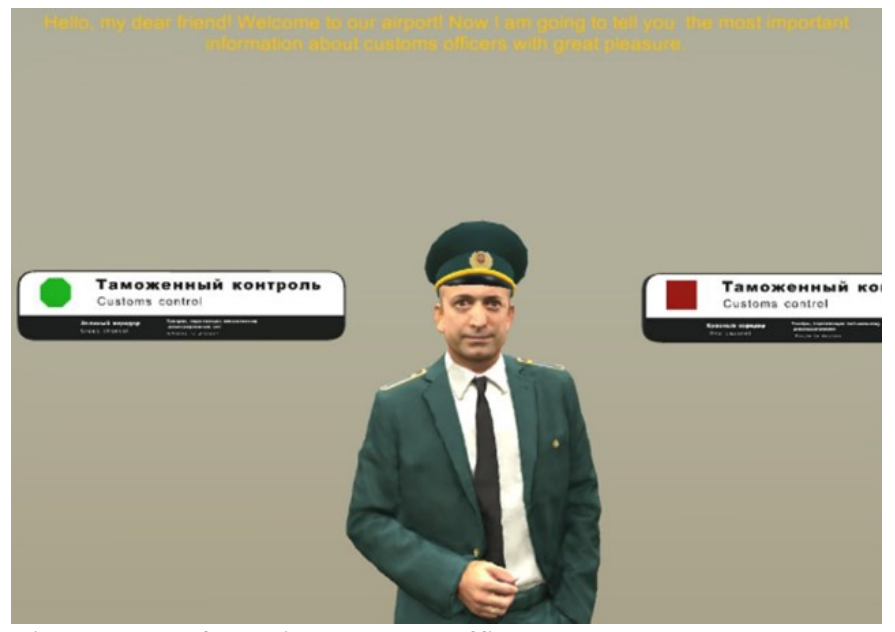

Fig.2 Screen from the customs officer

In the "Green Channel" hall the passenger can interact with the customs officer, learn the names of the possible goods and types of luggage. To test the learnt materials, the students should participate in the dialogues with missing words, the example of which is shown in Figure 3.

In the "Red Channel" hall, for example, the student can get acquainted with the names of the customs equipment, study the customs declaration, prohibited items list and other documents. For this it is necessary to proceed to this room and "approach" to the specified objects. Screen forms with examples of described items are shown in Figure 4.

In order to interact with customs personnel through dialogues in a foreign language, it is sufficient for a student to "approach" customs officers who are in each of the halls and differ from passengers of the airport by a form of customs service. The customs officer starts the dialogues which the student can first listen and then participate in it. The customs officer asks the passenger about his baggage, declaration, presence of prohibited items, their price and necessary documentation. He can ask you to open your suitcase, to put it on the belt, to go back or to arrest you.

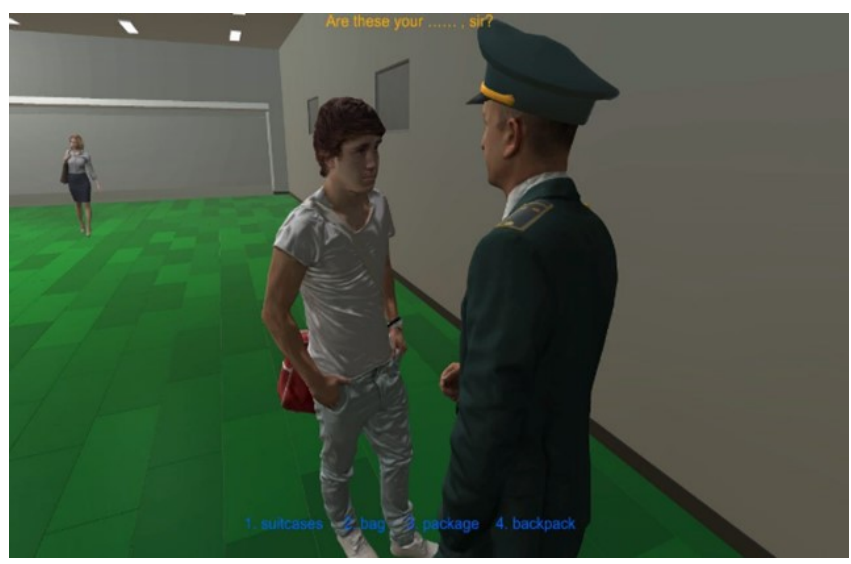

Fig.3 Screen form of the dialogue with missing words

To perform the interactive test, the operator must select the necessary training mode. The student is in the customs zone of the international airport already familiar to him. Following it, the student enters into dialogues with the staff. At the same time, some phrases in the dialogues are skipped and the student is offered to choose the necessary lexeme in accordance with the rules of the foreign language and the semantic load. In this case, the system indicates to the operator and the student the correctness of the chosen answer option. All answers are fixed by the system and on the basis of these data the training system "Virtual Customs" evaluates the student.

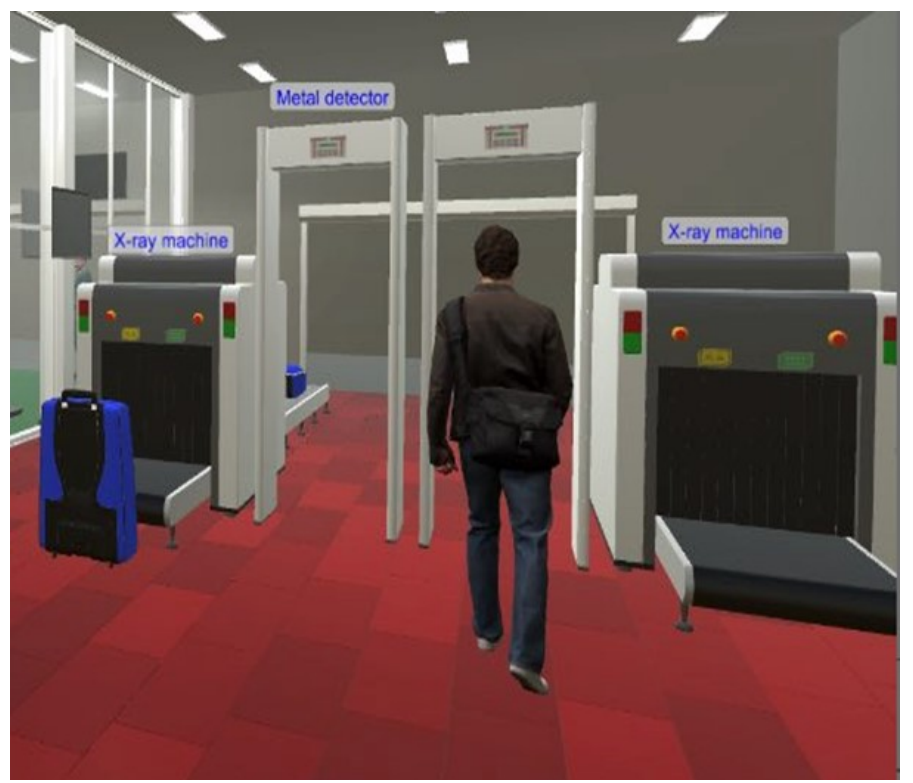

Fig. 4 Screen form of the Red Channel 
The functional purpose of the integrated learning system in a foreign language with VR/AR technologies "Virtual Customs" is:

- $\quad$ innovative method of teaching a foreign language;

- use of the latest VR/AR technologies in the process of learning a foreign language;

- interactive acquaintance with the customs device on the example of the customs point of the aviation node (international airport); preparation of teachers of a foreign language of a higher educational institution for conducting classes with the help of VR/AR technologies on the example of the training system "Virtual customs".

\section{CONCLUSION}

It should be mentioned that education using VR/AR allows you to visually con-duct lectures and seminars, conduct trainings, show the trainees all aspects of a real object or process, which as a whole gives a tremendous effect, improves the quality and speed of educational processes, reducing their cost. VR/AR technologies make it possible to make full use of the information that a person receives from the outside world. At the same time, we should not forget that $80 \%$ of the information a man perceives with the help of vision, as well as the fact that people remember $20 \%$ of what they see, $40 \%$ of what they see and hear, and $70 \%$ of what they see, hear and do.

In general, VR/AR is an ideal learning environment, and the possibilities of its technologies for teaching and research have extremely high potential for application.

Researchers claim that the formation effectiveness of the professionally oriented communicative foreign-language competence of students is due to the integration of selfeducation and multimedia support. We agree with the idea that today's successful learning with the support of the electronic educational environment and high-quality electronic educational resources can ensure the effective formation and development of professionally oriented communicative competence of students of non-linguistic specialties.

The potential of virtual reality technology is a full immersion in the professional environment and it allows students to build an individual way of studying the discipline on their own.

So, when using this approach to learning, it takes the shortest possible time and a minimum number of teachers is required to accomplish successfully the task of mastering a foreign language professionally. Being an ideal educational environment, virtual reality technology creates advantages for effective teaching a foreign language in connection with increasing motivation for learning and balanced development of all language skills.

\section{REFERENCES}

[1] J. Milton, "Measuring Second Language Vocabulary Acquisition", Bristol, Multilingual Matters, 342. 2007.

[2] P. Standen, and D. Brown, "Mobile learning and games in special education", In: The SAGE handbook of special education. SAGE, London, 2014, pp. 719- 730. ISBN 9781446210536

[3] H. Rheingold, "Foreword". In: Physical and Virtual Learning Spaces in Higher Education: Concepts for the Modern Learning Environment. IGI Publishing (IGI Global), Hershey, PA. United States, 2011.

[4] N.A. Nosov, "Virtual psychology", Moscow, Agraph, 2000.
[5] S.M. Grady, "Virtual reality: Simulating and enhancing the world with computers", New York, Facts on file, Inc., 34, 2003.

[6] H. Rheingold, "Virtual Reality", New York, NY, Summit, 56, 1991.

[7] S. McGlashan, and T. Axling, "Talking to Agents in Virtual Worlds", Swedish Institute of Computer Science, proc. Of VR-SIG Conf, Sweden, 231, 1996.

[8] J.C. Chwen, Y.L. Siew, and S.T. Chee, "A feasible group testing framework for producing usable virtual reality learning applications", Virtual Reality, June 2015, Volume 19, Issue 2, pp. 129-144.

[9] B. Meredith, and C.M. Byrne, "Summer students in virtual reality", Virtual reality: Applications and exploration, 1993, pp. 199218.

[10] B. Dalgarno, and M. Lee, "What are the learning affordances of 3-D virtual environments?", British Journal of Educational Technology 41.1, 2010, pp. 10-32.

[11] E.G. Doubleday, V.D. O'Loughlin, and A.F. Doubleday, "The virtual anatomy laboratory: Usability testing to improve an online learning resource for anatomy education", Anatomical sciences education 4.6, 2011, pp. 318-326.

[12] C. Freiberg, and Ramasamy-lyer Mahalinga-lyer, "Use of nonimmersive virtual reality in mechanical engineering laboratory", 2005, pp. 1-10.

[13] V. Ferk, "Students' understanding of molecular structure representations", International Journal of Science Education 25.10, 2003, pp. 1227-1245.

[14] Z. Merchant, "Effectiveness of virtual reality-based instruction on students' learning outcomes in K-12 and higher education: A metaanalysis", Computers \& Education 70, 2014, pp. 29-40.

[15] X. Ouyang, X. Yao, and X. Xie, "Design and Implementation of Virtual Lab Based on Internet", Computer Engineering 2, 2004.

[16] B. Dalgarno, "Characteristics of 3D environments and potential contributions to spatial learning". Doctoral dissertation, University of Wollongong. Retrieved April 18, 2005, from Australian Digital Theses, http://www.library.uow.edu.au/adtNWU/uploads/approved/adtNWU20050114.092913/public/02Whole.pdf p. 3

[17] J. Wann, and M. Mon-Williams, "What does virtual reality NEED? Human factors issues in the design of three-dimensional computer environments", International Journal of Human-Computer Studies, 44(6), 1996, pp. 829-847.

[18] M. Bricken, "Virtual Reality Learning Environments: Potentials and Challenges", Computer Graphics 25(3), 1991, pp. 178-184.

[19] J. Cromby, P. Standen, and D Brown, "Using Virtual Environments in Special Education", VR in the Schools 1(3), 1995, pp. 1-4.

[20] So-Y. Yoon, J. Laffey, and H. Oh, "Understanding usability and user experience of web-based 3D graphics technology", International Journal of Human-Computer Interaction 24.3, 2008, pp. 288-306.

[21] M. K. Stanney, et al., "Usability engineering of virtual environments (VEs): identifying multiple criteria that drive effective VE system design", International Journal of Human-Computer Studies 58.4, 2003, pp. 447-481.

[22] M. Bower, M.J.W. Lee, and B. Dalgarno, "Collaborative learning across physical and virtual worlds: Factors supporting and constraining learners in a blended reality environment", British Journal of Educational Technology, 48(2), 2017, pp. 407-430.

[23] Labzina, P.G., Gureev, M.V., Zhabin, M.E., Novalov, E.I.: Principles of teaching professionally-oriented foreign language in virtual reality. Vestnik of Samara State Technical University. Psychology and Pedagogy Series. 4(36), 79-89 (2017).

[24] Popova, T.P., Nenasheva, T.A: Information technologies in teaching foreign languages in higher education (model of mixed education). Historical and social-educational thought. 6-1, 218-226 (2016).

[25] Makarova, O. Yu.: Implementation of the principle of professional orientation in the process of training a social worker: thesis ... cand. ped. sciences: 13.00.01. Kazan (2004).

[26] V.V. Dobrova, and P.G. Labzina, "Virtual Reality in Teaching Foreign Languages", Vestnik of Samara State Technical University, Psychological and Pedagogical Sciences Series, №4 (32), 2016, p. 17.

[27] T. Axling, "Collaborative configuration in virtual environments", Virtual Reality 3: 59, 1998. https://doi.org/10.1007/BF01409798 